\title{
Desempenho e Características de Carcaça de Novilhos Suplementados no Período das Águas 1
}

\author{
Joanis Tilemahos Zervoudakis ${ }^{2}$, Mário Fonseca Paulino ${ }^{3}$, Edenio Detmann², \\ Rogério de Paula Lana ${ }^{3}$, Sebastião de Campos Valadares Filho ${ }^{3}$, Paulo Roberto Cecon ${ }^{4}$, \\ Domingos Sávio de Queiroz ${ }^{5}$, Andréia Luciane Moreira ${ }^{6}$
}

\begin{abstract}
RESUMO - Avaliaram-se os efeitos da suplementação concentrada de novilhos, durante o período das águas, sobre o desempenho e características da carcaça. Foram utilizados 49 novilhos mestiços, mantidos em pastagem de Brachiaria decumbens. O experimento foi conduzido em três períodos experimentais, segundo um delineamento inteiramente casualizado. Foram fornecidos sal mineral (SAL), suplementos à base de milho e farelo de soja, com 20\% PB, em níveis de 1,0 e 2,0 kg/dia (MFS1 e MFS2), e suplementos à base de farelo de trigo e farelo de soja, com 20\% PB, em níveis de 1,0 e 2,0 kg/dia (FTFS1 e FTFS2), fornecidos diariamente. Não foram encontradas diferenças entre os tratamentos sobre ganho de peso médio diário (GMD) e ganho total (GDP Total). Os GMD foram: 0,887; 0,936; 1,047; 0,943; e 1,012 kg/animal/dia, respectivamente, para os tratamentos SAL, MFS1, MFS2, FTFS1 e FTFS2. Os animais submetidos aos diferentes tratamentos não exibiram diferenças nas características físicas e químicas da carcaça. Não houve diferenças quanto ao rendimento de carcaça dos novilhos dos diferentes tratamentos, que foi, em média, de 52,19\%.
\end{abstract}

Palavras-chave: braquiária, composição corporal, suplementos, terminação

\section{Performance and Characteristics of Carcass of Supplemented Steers during the Rainny Season}

\begin{abstract}
The effects of concentrate supplementation of steers during the rainny season on the performance and physical and traits of the carcass were evaluated. Fourty nine crossbreds steers were used, maintained on pastures of Brachiaria decumbens. The experiment was carried out in three experimental periods, according to a complete randomized design. The following supplements were daily fed at 10 a.m.: mineral salt (SALT), corn and soybean meal based supplements, with $20 \% \mathrm{CP}$, at the levels of 1.0 and $2.0 \mathrm{~kg}$ (CSBM1 and CSBM2) and wheat bran and soybean meal based supplements, with $20 \% \mathrm{CP}$, at the levels of 1.0 and $2.0 \mathrm{~kg}$ (WMSBM1 and WMSBM2). There was no treatment effect on average daily gain (ADG) and body weight (BW). The ADG were: 0.887, 0.936, 1.047, 0.943 and $1.012 \mathrm{~kg} / \mathrm{animal} / \mathrm{day}$, respectively, for the treatments SALT, CSBM1, CSBM2, WMSBM1 and WMSBM2. The animals submitted to the different treatments did not exhibit differences in the physical and chemical characteristics of the carcass. No differences were observed for the steers carcass yield, which was, in average, of $52.19 \%$.
\end{abstract}

Key Words: braquiaria, body composition, finishing, supplements

\section{Introdução}

Mudanças advindas da estabilidade econômica, melhoria do poder aquisitivo, conscientização de seus direitos, preocupação com saúde e bem-estar, entre outros fatores, contribuíram de forma marcante para que o consumidor moderno se torne mais exigente na busca de produtos que atendam os seus anseios (LUCHIARI FILHO, 1998). Frente a estes fatores, torna-se essencial, a adaptação dos sistemas produtivos, industrial e varejistas no sentido de ofertar o produto requisitado pelos consumidores.
A extensão territorial e de pastagens, bem como a terminação de bovinos em sistemas de pastejo, favorece a produção e terminação de bovinos em condições de menor acúmulo de gordura corporal. Neste aspecto, as raças zebuínas são também favorecidas por apresentarem um menor teor de gordura na carcaça, do que quando comparadas a algumas raças de origem européia e principalmente britânicas (LUCHIARI FILHO, 1998). Em função destes aspectos será de fundamental importância, a obtenção de um produto com um nível mínimo de gordura, que propicie um adequado resfriamento da

\footnotetext{
${ }^{1}$ Parte da tese do primeiro autor, apresentada à Univ. Fed. de Viçosa, para obtenção do título de Magister Scientiae em Zootecnia.

2 Zootecnista, MS, Estudante de Doutorado, DZO-UFV, Viçosa-MG, 36571-0005. E.mail: joanis@alunos.ufv.br

3 Professor do Departamento de Zootecnia, Univ. Federal de Viçosa, Pesquisador do CNPq, Viçosa-MG, CEP 36571-005.

4 Professor do Departamento de Informática, Univ. Federal de Viçosa, Viçosa-MG, CEP 36571-005.

${ }^{5}$ Pesquisador da EPAMIG, Viçosa - MG - CEP 36571-000.

6 Zootecnista, MS, Estudante de Doutorado, UNESP, Jaboticabal.
} 
carcaça e processamento da mesma, e que possa também garantir um produto de boa qualidade ao consumidor.

Geralmente, o nutriente mais limitante para reprodução, ganho de peso e produção de leite de animais mantidos em regimes exclusivos de pastagens, é a energia. Isto se deve principalmente ao insuficiente consumo e ao baixo valor energético da maioria das forrageiras (NOLLER, et al., 1996). Apesar de ser vital importância, energia é considerada como sendo um nutriente de natureza secundária, dando-se uma maior ênfase à correção das deficiências protéicas das pastagens.

$O$ fornecimento de suplementação de energia apenas, não poderia por si só, eliminar tanto as deficiências energéticas como as protéicas, por não atender completamente esta última. Por outro lado, tanto a deficiência em energia como em proteína podem ser eliminadas apenas pela correção na deficiência protéica (PAULINO et al., 1982).

Em função disto, animais em pastejo estão sujeitos a muitas alterações tanto na quantidade como na qualidade das forragens consumidas. Sendo assim, em alguns períodos há consumo de energia suficiente para acumular reservas corporais, enquanto que em outros, o consumo é suficiente somente para a mantença ou há catabolismo das reservas corporais. A velocidade de digestão mais lenta dos componentes fibrosos das forragens, quando comparados aos carboidratos não estruturais dos concentrados, torna de fundamental importância a suplementação de animais em pastejo, com concentrados de mais rápida e alta digestibilidade, quando se almeja ganhos e desempenhos diferenciados em determinadas etapas do processo produtivo.

A proporção dos tecidos na carcaça no momento do abate é o aspecto da composição do animal que mais importância tem para o consumidor e portanto, determina em grande parte o valor econômico da carcaça (BERG e BUTTERFIELD, 1976). O peso de abate, o sexo, a nutrição e a raça podem afetar a composição da carcaça e são os fatores mais importantes que os produtores dispõem, na tentativa de alterar a composição da carcaça.

Os objetivos do presente estudo foram avaliar o desempenho e características da carcaça de novilhos mestiços Holandês-Zebu castrados, mantidos em regime de suplementação concentrada a pasto no período das águas.

\section{Material e Métodos}

O presente estudo foi realizado na Fazenda Experimental de Felixlândia, da Empresa de Pesquisa Agropecuária de Minas Gerais (EPAMIG), em Felixlândia-MG, no período de janeiro e maio de 1998.

A área experimental constituiu-se de cinco piquetes de oito hectares, com topografia plana, coberta uniformemente com a gramínea Brachiaria decumbens, divididos por cerca eletrificada, sendo providos de bebedouro e comedouro coberto.

Foram utilizados quarenta e nove animais mestiços Holandês-Zebu, castrados, com idade e peso médios iniciais de 18 meses e $278 \mathrm{~kg}$, respectivamente, originários da EPAMIG, sendo escolhidos em função do grau de sangue, da idade e do peso, dos quais quatro foram destinados ao abate inicial de referência e os demais, ao ensaio de desempenho.

Os animais remanescentes foram distribuídos em cinco lotes uniformes, quanto ao peso vivo e à condição corporal, e, posteriormente, designados, aleatoriamente, aos seguintes tratamentos:

T1 - controle, sem suplementação (SAL) (Salt);

T2 - suplemento constituído de milho e farelo de soja, fornecido em nível de $1 \mathrm{~kg} / \mathrm{dia}$ (MFS1) (CSBM1);

T3 - suplemento constituído de milho e farelo de soja, fornecido em nível de $2 \mathrm{~kg} /$ dia (MFS2) (CSBM2);

T4 - suplemento constituído de farelo de trigo e farelo de soja, fornecido em nível de $1 \mathrm{~kg} / \mathrm{dia}$ (FTFS1) (WMSBM1); e

T5 - suplemento constituído de farelo de trigo e farelo de soja, fornecido em nível de $2 \mathrm{~kg} / \mathrm{dia}$ (FTFS2) (WMSBM2).

Os suplementos foram previamente balanceados, em função dos valores de composição relatados por CAMPOS (1995), objetivando atingir nível de $20 \%$ de proteína bruta $(\mathrm{PB})$, com base na matéria natural (Tabela 1), sendo fornecidos diariamente aos animais às $10 \mathrm{~h}$. Os animais em todos os tratamentos possuíam livre acesso à água e mistura mineral, sendo rotacionados entre os piquetes a cada 28 dias.

Procedeu-se ao abate de quatro animais (referência) no início do experimento e de três animais de cada tratamento no final do experimento, totalizando 19 animais, objetivando a determinação da composição física e química e das características das carcaças dos bovinos. Os abates ocorreram por concussão cerebral e posterior secção da veia jugular. 
Rev. bras. zootec.

Tabela 1 - Composição dos suplementos (\%), com base na matéria natural

Table 1 - Composition of supplements (\%), in as fed basis

\begin{tabular}{|c|c|c|c|}
\hline \multirow[b]{2}{*}{$\begin{array}{l}\text { Ingredientes } \\
\text { Ingredients }\end{array}$} & \multicolumn{3}{|c|}{$\begin{array}{l}\text { Tratamentos } \\
\text { Treatments }\end{array}$} \\
\hline & $\begin{array}{l}\mathrm{Sal}^{1} \\
\text { Salt }\end{array}$ & $\begin{array}{c}\text { MFS1/MFS2 } \\
C S B M 1 / C S B M 2\end{array}$ & $\begin{array}{c}\text { FTFS1/FTFS2 } \\
W M S B M 1 / W M S B M 2\end{array}$ \\
\hline $\begin{array}{l}\text { Mistura mineral } \\
\text { Mineral premix }\end{array}$ & 100 & - & - \\
\hline $\begin{array}{l}\text { Milho grão } \\
\text { Corn grain }\end{array}$ & - & 67,6 & - \\
\hline $\begin{array}{l}\text { Farelo de trigo } \\
\text { Wheat middlings }\end{array}$ & - & - & 83,3 \\
\hline $\begin{array}{l}\text { Farelo de soja } \\
\text { Soybean meal }\end{array}$ & - & 32,4 & 16,7 \\
\hline $\begin{array}{l}1 \text { Composição perc } \\
48,01 \text {; sulfato de } \\
\text { cobalto, } 0,05 ; \text { e i } \\
1 \text { Percentage compos } \\
\text { zinc sulfate, } 1.50 ; 0 \\
\text { iodate, } 0.03 \text {. }\end{array}$ & : dic & $\begin{array}{l}\text { sfato bicálcico, } \\
50 ; \text { sulfato de } \\
\text { jotássio, } 0,03 \text {. } \\
\text { ium phosfate, } 50 \text {. }\end{array}$ & $\begin{array}{l}\text {,01; cloreto de sódio, } \\
\text { bre, } 0,40 \text {; sulfato de } \\
\text {; sodium chloride, } 48.01 \text {, }\end{array}$ \\
\hline
\end{tabular}

Logo após o abate de cada animal, foram pesadas e coletadas amostras de sangue, couro, cauda, aparelho reprodutor, rúmen-retículo, omaso, abomaso, intestino delgado, intestino grosso, mesentério, gordura interna, carne industrial, fígado, coração, rins, pulmão, traquéia, baço, língua e esôfago. Para um animal abatido de cada tratamento, foram pesadas, dissecadas e retiradas amostras de uma cabeça e um pé.

As duas meia-carcaças foram pesadas quentes no momento do abate. $\mathrm{O}$ comprimento medido na meiacarcaça direita foi tomado da porção anterior medial da primeira costela até o ponto médio da curvatura do osso púbis, com o auxílio de uma fita métrica.

O estudo do rendimento dos cortes primários foi realizado na meia-carcaça direita. Separou-se o dianteiro do traseiro entre a quinta e a sexta costelas, e o dianteiro foi então dividido em acém e paleta completos. O traseiro foi dividido em ponta de agulha e traseiro especial (corte serrote), o qual foi subdividido em coxão e alcatra completa.

Posteriormente, coletou-se uma amostra representativa da meia-carcaça esquerda, correspondendo à seção da $9^{\mathrm{a}}$ à $11^{\mathrm{a}}$ costela (seção $\mathrm{HH}$ ), de acordo com HANKINS e HOWE (1946), objetivando posteriores dissecações, avaliações dos componentes físicos das carcaças e análises laboratoriais. Na meiacarcaça esquerda, foram também medidas, na altura da $12^{a}$ costela, a área da seção do músculo Longissimus dorsi (área de olho de lombo - AOL) e a espessura de gordura subcutânea.
A amostragem da massa forrageira e a disponibilidade de forragem em cada piquete experimental foram determinadas no primeiro dia de cada período experimental, por meio do corte de dez áreas delimitadas por um quadrado de $1 \mathrm{x} 1 \mathrm{~m}$, escolhidas ao acaso dentro de cada piquete e cortadas rente ao solo, conforme relatado por McMENIMAN (1997).

Para se amostrar o pasto consumido, em cada período experimental, foram utilizados cinco bovinos $1 / 2$ sangue Limousin x Nelore, castrados, com idade e peso médios iniciais de 22 meses e $396 \mathrm{~kg}$, fistulados no esôfago, os quais foram mantidos à parte em cinco piquetes de gramínea Brachiaria decumbens, sendo transferidos para os piquetes experimentais, por ocasião das coletas. As amostras coletadas, representativas de cada piquete experimental, foram congeladas, para posteriores processamento e análises laboratoriais.

O processamento, bem como as análises bromatológicas de todas as amostras, foi realizado no Laboratório de Nutrição Animal do Departamento de Zootecnia da Universidade Federal de Viçosa. Procedeu-se às análises de cada amostra de forragem e de suplemento, com relação aos seus teores de matéria seca (MS), proteína bruta $(\mathrm{PB})$, cinzas, extrato etéreo $(\mathrm{EE})$, magnésio $(\mathrm{Mg})$, cálcio $(\mathrm{Ca})$, fósforo $(\mathrm{P})$ e potássio $(K)$, segundo metodologia descrita por SILVA (1990). A determinação dos teores de fibra em detergente neutro (FDN) foi feita segundo técnica descrita por VAN SOEST et al. (1991). Os carboidratos totais (CHOT) foram obtidos por intermédio da equação: $100-(\% \mathrm{~PB}+\% \mathrm{EE}+\%$ Cinzas $)$ e os carboidratos não-estruturais (CNE), pela diferença entre CHOT e FDN (SNIFFEN et al., 1992). A composição bromatológica da extrusa e dos suplementos é mostrada na Tabela 2.

Os componentes físicos (músculo, tecido adiposo e ossos) e a composição química dos mesmos (teores de proteína e gordura) foram determinados nas seções retiradas da meia-carcaça esquerda (seção HH).

As proporções de músculo, tecido adiposo e ossos da carcaça foram estimadas com base nas proporções destes componentes na seção HH, segundo as equações desenvolvidas por HANKINS e HOWE (1946):

$\begin{array}{ll}\text { Músculo } & \mathrm{Y}=16,08+0,80 \mathrm{X} \\ \text { Tecido adiposo } & \mathrm{Y}=3,54+0,80 \mathrm{X} \\ \text { Ossos } & \mathrm{Y}=5,52+0,57 \mathrm{X}\end{array}$

em que: $X$ é a porcentagem do componente na seção HH.

$\mathrm{O}$ peso do corpo vazio (PCVZ) dos animais foi determinado pela soma do peso de carcaça, cabeça, 
Tabela 2 - Teores médios de matéria seca (MS), matéria orgânica (MO), proteína bruta (PB), extrato etéreo (EE), carboidratos totais (CHOT), fibra em detergente neutro (FDN), carboidratos não-estruturais (CNE), cinzas, Mg, Ca, $\mathrm{P}$ e K, com base na matéria seca, para a extrusa e para os suplementos à base de milho e farelo de soja (MFS 1 e 2) e farelo de trigo e farelo de soja (FTFS 1 e 2)

Table 2 - Average content of dry matter (DM), organic matter (OM), crude protein (CP), ether extract (EE), total carboydrate (TC), neutral detergent fiber (NDF), non-structural carboydrates (NSC), ash, $\mathrm{Mg}, \mathrm{Ca}, \mathrm{P}$ and $\mathrm{K}$, on dry matter basis, of extrusa and corn and soybean meal (CSBM 1 and 2) and wheat middlings and soybean meal (WMSBM 1 and 2) based supplements

\begin{tabular}{|c|c|c|c|c|c|}
\hline \multirow[t]{2}{*}{ Itens } & \multicolumn{3}{|c|}{$\begin{array}{l}\text { Extrusa } \\
\text { Extrusa }\end{array}$} & \multicolumn{2}{|c|}{$\begin{array}{l}\text { Suplemento } \\
\text { Supplements }\end{array}$} \\
\hline & $\begin{array}{c}\text { Período } 1 \\
\text { Period } 1\end{array}$ & $\begin{array}{c}\text { Período } 2 \\
\text { Period } 2\end{array}$ & $\begin{array}{c}\text { Período } 3 \\
\text { Period } 3 \\
\end{array}$ & $\begin{array}{l}\text { MFS } \\
C S B M\end{array}$ & $\begin{array}{c}\text { FTFS } \\
W M S B M\end{array}$ \\
\hline $\operatorname{MS}(D M), \%$ & 12,7 & 13,3 & 15,5 & 81,7 & 79,5 \\
\hline $\mathrm{MO}(O M)^{1}$ & 89,5 & 89,8 & 90,9 & 96,6 & 93,7 \\
\hline $\mathrm{PB}(C P)^{1}$ & 9,1 & 8,5 & 8,9 & 25,8 & 24,3 \\
\hline $\mathrm{EE}(E E)^{1}$ & 0,5 & 0,7 & 1,2 & 0,4 & 0,1 \\
\hline $\operatorname{CHOT}(T C)^{1}$ & 79,9 & 80,7 & 80,8 & 69,8 & 69,2 \\
\hline $\mathrm{FDN}(N D F)^{\mathbf{1}}$ & 72,3 & 73,6 & 72,6 & 11,9 & 44,3 \\
\hline $\mathrm{CNE}(C N S)^{1}$ & 7,6 & 7,1 & 8,2 & 57,9 & 24,9 \\
\hline Cinzas $(A s h)^{1}$ & 10,5 & 10,2 & 9,1 & 3,4 & 6,3 \\
\hline $\operatorname{Mg}^{1}$ & 0,07 & 0,06 & 0,10 & - & - \\
\hline $\mathrm{Ca}^{1}$ & 0,22 & 0,19 & 0,23 & - & - \\
\hline $\mathrm{P}^{1}$ & 0,22 & 0,18 & 0,15 & - & - \\
\hline $\mathrm{K}^{1}$ & 0,99 & 0,79 & 1,05 & - & - \\
\hline
\end{tabular}

$1 \% \mathrm{MS}(\% \mathrm{DM})$.

couro, sangue, pés, cauda, órgãos e vísceras. Estabeleceu-se uma relação entre o peso do corpo vazio (PCVZ) e o peso vivo (PV) dos quatro animaisreferência, para ser utilizado na estimativa do PCVZ inicial dos animais abatidos no final do experimento.

As análises referentes ao desempenho e às características de carcaça dos bovinos foram conduzidas em um delineamento inteiramente casualizado, segundo o modelo:

$$
Y_{i j}=\mu+t_{i}+e_{i j}
$$

em que: $Y_{i j}=$ valor observado na unidade experimental que recebeu o suplemento $i$ na repetição $j$; $\mu=$ média geral; $\mathrm{t}_{\mathrm{i}}=$ efeito do suplemento $\mathrm{i}$, sendo $\mathrm{i}=1,2,3,4$ e $5 ; \mathrm{j}=1,2,3,4,5 \ldots . .9 ; \mathrm{e} \mathrm{e}_{\mathrm{ij}}=$ erro aleatório, associado a cada observação.
Para comparações entre médias, adotou-se o teste de Newman Keulls, sendo que todas as análises foram realizadas por intermédio do programa SAEG - UFV (1995), adotando-se o nível de significância de $5 \%$.

\section{Resultados e Discussão}

Os valores referentes ao peso vivo em jejum inicial (PVJinic.), peso vivo em jejum final (PVJfinal), ganho total (GDPtotal) e ganho médio diário (GMD), em função dos diferentes suplementos, são apresentados na Tabela 3.

Não foram verificadas diferenças $(\mathrm{P}>0,05)$ entre as variáveis avaliadas, embora o GDP total dos

Tabela 3 - Médias e coeficientes de variação (CV) para peso vivo em jejum inicial (PVJ inic.) e final (PVJ final) e ganho total (GDP Total) e médio diário (GMD), em função dos diferentes tratamentos

Table 3 - Means and coefficients of variation (CV) of live weight in fasting initial (LWFI) and final (LWFF) and total gain (TG) and average daily (ADG), according to different treatments

\begin{tabular}{|c|c|c|c|c|c|c|c|}
\hline \multirow[b]{2}{*}{ Itens } & \multirow[b]{2}{*}{$\begin{array}{l}\text { Sal } \\
\text { Salt }\end{array}$} & \multicolumn{4}{|c|}{$\begin{array}{c}\text { Tratamento } \\
\text { Treatment }\end{array}$} & \multirow[b]{2}{*}{$\begin{array}{l}\text { Média } \\
\text { Mean }\end{array}$} & \multirow[b]{2}{*}{$\mathrm{CV}(\%)$} \\
\hline & & $\begin{array}{l}\text { MFS1 } \\
\text { CSBM1 }\end{array}$ & $\begin{array}{l}\text { MFS2 } \\
C S B M 2 \\
\end{array}$ & $\begin{array}{c}\text { FTFS1 } \\
W M S B M 1\end{array}$ & $\begin{array}{c}\text { FTFS2 } \\
W M S B M 2 \\
\end{array}$ & & \\
\hline PVJ inicial (LWFI), $\mathrm{kg}$ & $281^{\mathrm{a}}$ & $279^{\mathrm{a}}$ & $278^{\mathrm{a}}$ & $277^{\mathrm{a}}$ & $276^{\mathrm{a}}$ & 278 & 10,44 \\
\hline PVJ final $(L W F F), \mathrm{kg}^{1}$ & $382,0^{\mathrm{a}}$ & $386,0^{\mathrm{a}}$ & $397,3^{\mathrm{a}}$ & $384,4^{\mathrm{a}}$ & $391,0^{\mathrm{a}}$ & 388,1 & 8,7 \\
\hline GDP Total $(T G), \mathrm{kg}^{1}$ & $101,1^{\mathrm{a}}$ & $106,7^{\mathrm{a}}$ & $119,3^{\mathrm{a}}$ & $107,6^{\mathrm{a}}$ & $115,3^{\mathrm{a}}$ & 110,0 & 14,2 \\
\hline $\operatorname{GMD}(A D G), \mathrm{kg}^{1}$ & $0,89^{\mathrm{a}}$ & $0,94^{\mathrm{a}}$ & $1,05^{\mathrm{a}}$ & $0,94^{\mathrm{a}}$ & $1,01^{\mathrm{a}}$ & 0,96 & 14,3 \\
\hline
\end{tabular}

1 Médias em uma mesma linha, seguidas por letras diferentes, são diferentes $(P<0,05)$ pelo teste $F$.

1 Means, within a row, followed by different letters are different $(P<.05)$ by $F$ test. 
animais submetidos aos suplementos MFS2 e FTFS2 tenha sido, respectivamente, 18 e $14 \%$ superior ao dos animais testemunha (SAL). Resultados semelhantes ao do presente estudo foram encontrados por PAULINO et al. (1996), que avaliaram o efeito dos farelos de soja e algodão em suplementos múltiplos sobre o desenvolvimento de novilhas mestiças em pastagens de capim-jaraguá, durante o período das águas. Esses autores também não observaram diferenças expressivas entre os diferentes suplementos e o tratamento testemunha (sal mineral). Entretanto, PAULINO et al. (1996) ressaltaram que o melhor desempenho, embora sem significância estatística, dos animais que receberam o suplemento contendo farelo de soja pode ser creditado à melhor qualidade e ao balanço de aminoácidos da porção não-degradada da proteína do farelo de soja que atingiu o intestino delgado.

Os menores valores obtidos com relação ao GMD para o tratamento testemunha (sal mineral), no experimento de PAULINO et al. (1996), 0,624 kg/dia, quando comparados ao tratamento testemunha do presente estudo $(0,887 \mathrm{~kg} / \mathrm{dia})$, possivelmente ocorreram em virtude de as pastagens utilizadas se constituírem de capim-jaraguá, que possui reduzido valor nutricional, acarretando, portanto, menores aceitação e consumo pelos animais. Neste estudo, a área de pastejo era formada por Brachiaria decumbens, a qual, além de propiciar maior consumo, também promoveu maior aporte de nutrientes para os animais submetidos ao tratamento com sal mineral, em razão de sua boa composição bromatológica (Tabela 2).

EUCLIDES et al. (1998), avaliando diferentes alternativas de manejo alimentar de bovinos em pastagens de Brachiaria decumbens, com o fornecimento de suplementos contendo $75 \%$ de MDPS e $25 \%$ de farelo de soja, fornecidos em quantidades equivalentes a $0,8 \%$ do peso vivo, encontraram, no período das águas, resultados médios inferiores, para $\operatorname{GMD}(0,417$ $\mathrm{kg} / \mathrm{animal} / \mathrm{dia}$ ), aos observados no presente estudo, para todos os tratamentos.

Além da presença do efeito substitutivo, destacam-se também como fatores que podem ter contribuído para o menor desempenho dos animais de EUCLIDES et al. (1998) menor disponibilidade de matéria seca (MS) por hectare $(2,0$ toneladas de $\mathrm{MS} / \mathrm{ha})$ e valor nutricional inferior $(6,8 \% \mathrm{~PB}$ e $47,8 \%$ DIVMO) ao da forragem utilizada no presente experimento (8,8\% PB e 65,65\% DIVMS). Nesse sentido, a melhor qualidade da pastagem, aliada à elevada disponibilidade de MS/ha encon- trada neste estudo (Tabela 4), possivelmente possibilitou maior seletividade da forragem ingerida pelos animais, propiciando, dessa forma, melhor desempenho dos mesmos.

HESS et al. (1996), suplementando novilhos em regime de pastejo, no período das águas, com milho grão ou farelo de trigo, obtiveram aumentos no desempenho produtivo dos animais suplementados, quando comparados aos do tratamento testemunha (sem suplementação); efeito não observado neste trabalho.

DETMANN et al. (2001), utilizando animais em pastagens de Brachiaria decumbens, durante o mesmo período, submetidos aos mesmos suplementos deste estudo, constatou que os animais do tratamento testemunha (sal mineral) apresentaram consumo numericamente maior que os bovinos submetidos às demais formas de suplementação, o que poderia explicar os desempenhos semelhantes dos animais do tratamento testemunha, com relação aos dos animais suplementados.

O consumo de MS encontrado por DETMANN et al. (2001), associado à composição bromatológica apresentada na Tabela 2, almeja ganhos médios diários em torno de $0,965 \mathrm{~kg} / \mathrm{animal}$, como verificado neste estudo. Uma extrapolação do NRC (1996) feita para ganho em torno de $0,96 \mathrm{~kg} / \mathrm{dia}$, para um animal com $350 \mathrm{~kg}$ e $28 \%$ de gordura corporal, sugere consumo de MS/dia de 8,89 vs 8,48 $\mathrm{kg}$ de MS, consumo médio encontrado por DETMANN et al. (2001). Assim, os valores encontrados para ganho médio diário (GMD), neste estudo, tomando-se como base o consumo determinado por DETMANN et al. (2001), são compatíveis com o consumo de MS/dia preconizado pelo NRC (1996), para GMD similares aos obtidos neste estudo.

Tabela 4 - Disponibilidade média de matéria seca (MS), em $\mathrm{kg} / \mathrm{ha}$, e coeficientes de variação (CV\%) dos piquetes experimentais, nos diferentes períodos

Table 4 - Average availability of dry matter (DM), $\mathrm{kg} / \mathrm{ha}$, and coefficient of variration (CV\%) of experimental paddocks, according to different treatments

Disponibilidade MS (kg/ha) CV(\%) Availability DM $(\mathrm{kg} / \mathrm{ha})$

\begin{tabular}{lcc}
\hline $\begin{array}{l}\text { Período 1 } \\
\text { Period 1 }\end{array}$ & 7739 & 33,0 \\
$\begin{array}{l}\text { Período 2 } \\
\text { Period 2 }\end{array}$ & 6999 & 34,5 \\
Período 3 & & \\
Period 3 & 5771 & 24,9 \\
\hline
\end{tabular}


O rendimento de carcaça, expresso em relação ao peso vivo em jejum (PVJ) ou ao peso corporal vazio (PCVZ), assim como o ganho diário de peso de corpo vazio (GPCVZ), não foi influenciado pela suplementação $(\mathrm{P}>0,05)$, apresentando valores médios de $52,19 \% ; 61,41 \%$; e $1,00 \mathrm{~kg} /$ dia, respectivamente (Tabela 5).

Os rendimentos de carcaça em relação ao PCVZ foram próximos aos relatados por JORGE (1997b), 62,56\%; FERREIRA et al. (1997), 65,33\%; e PERON (1991), 62,85; 62,46; e 61,97\%, respectivamente, para novilhos Nelore-Holandês, Gir-Holandês e 3/4 Holandês-Gir.

Os rendimentos dos cortes básicos, dianteiro, paleta, acém, traseiro total, traseiro especial, alcatra completa, coxão e ponta de agulha, expressos em relação ao peso da meia-carcaça direita quente, de novilhos mestiços Holandês-Zebu, submetidos aos diferentes suplementos, encontram-se na Tabela 6.

As análises de variância não apontaram diferenças $(\mathrm{P}>0,05)$ entre as variáveis avaliadas para os animais submetidos aos diferentes suplementos. Os resultados obtidos foram semelhantes aos de PERON (1991), que, trabalhando com animais mestiços castrados e padrões raciais similares aos deste estudo, porém em confinamento, não encontrou diferenças $(\mathrm{P}>0,05)$ para os rendimentos dos cortes básicos da carcaça, entre os diferentes grupos genéticos avaliados.

Não se verificaram diferenças acentuadas quanto ao rendimento dos quartos traseiro e dianteiro entre

Tabela 5 - Valores médios de peso (Peso Carc.), rendimento de carcaça em função do peso de jejum (RCPVJ), peso corporal vazio (RCPCVZ) e ganho diário de peso de corpo vazio (GPCVZ), de acordo com os diferentes tratamentos

Table 5 - Average values of carcass weight (CW), carcass yield in function of fasting weight (YCFW), empty body weight (YEBW) and daily gain of empty body weight (DGEBW), according to different treatments

\begin{tabular}{|c|c|c|c|c|c|c|c|}
\hline \multirow[b]{2}{*}{ Item } & \multirow[b]{2}{*}{$\begin{array}{l}\text { Sal } \\
\text { Salt }\end{array}$} & \multicolumn{4}{|c|}{$\begin{array}{c}\text { Tratamento } \\
\text { Treatment }\end{array}$} & \multirow[b]{2}{*}{$\begin{array}{l}\text { Média } \\
\text { Mean }\end{array}$} & \multirow[b]{2}{*}{$\mathrm{CV}(\%)$} \\
\hline & & $\begin{array}{l}\text { MFS1 } \\
C S B M 1\end{array}$ & $\begin{array}{l}\text { MFS2 } \\
\text { CSBM2 }\end{array}$ & $\begin{array}{c}\text { FTFS1 } \\
W M S B M 1\end{array}$ & $\begin{array}{c}\text { FTFS2 } \\
\text { WMSBM2 }\end{array}$ & & \\
\hline $\begin{array}{l}\text { Peso carc. }(\mathrm{kg})^{1} \\
C W\end{array}$ & $210,7^{\mathrm{a}}$ & $216,0^{\mathrm{a}}$ & $232,9^{\mathrm{a}}$ & $213,9^{\mathrm{a}}$ & $214,1^{\mathrm{a}}$ & 217,5 & 8,9 \\
\hline $\operatorname{RCPCVZ}(\%)^{1}(\mathrm{YCWF})$ & $60,7^{\mathrm{a}}$ & $61,9^{\mathrm{a}}$ & $61,8^{\mathrm{a}}$ & $61,8^{\mathrm{a}}$ & $60,8^{a}$ & 61,4 & 2,2 \\
\hline $\operatorname{RCPVJ}(\%)^{1}(Y E B W)$ & $49,7^{\mathrm{a}}$ & $53,9^{\mathrm{a}}$ & $52,8^{\mathrm{a}}$ & $53,8^{\mathrm{a}}$ & $50,6^{\mathrm{a}}$ & 52,2 & 4,1 \\
\hline GPCVZ $(\mathrm{kg} / \mathrm{dia})^{1}$ & $0,84^{\mathrm{a}}$ & $1,09^{\mathrm{a}}$ & $1,13^{\mathrm{a}}$ & $0,98^{\mathrm{a}}$ & $0,99^{\mathrm{a}}$ & 1,00 & 14,4 \\
\hline
\end{tabular}

${ }^{1}$ Médias em uma mesma linha, seguidas por letras diferentes, são diferentes $(P<0,05)$ pelo teste $F$.

${ }^{1}$ Means, within a row, followed by different letters are different $(P<.05)$ by $F$ test.

Tabela 6 - Médias do rendimento do dianteiro (RD), da paleta (RPAL), do acém (RACÉM), do traseiro total (RTT), do traseiro especial (RTE) da alcatra completa (RALC), do coxão (RCOX) e da ponta de agulha (RPA) e coeficientes de variação (CV\%), em função dos diferentes tratamentos

Table 6 - Means of hindquarter yield (YHQ), shoulder yield (SY), acem yield (AY), forequarter yield (FQY), pistola style cut yield (PSCY), whole rump yield (WRY), round yield (RY), spare ribs yield $(S R Y)$ and coefficients of variation, according to different treatments

\begin{tabular}{|c|c|c|c|c|c|c|c|}
\hline \multirow{3}{*}{$\begin{array}{l}\text { Parâmetro } \\
\text { Parameter }\end{array}$} & \multirow{3}{*}{$\begin{array}{l}\text { Sal } \\
\text { Salt }\end{array}$} & \multicolumn{4}{|c|}{$\begin{array}{c}\text { Tratamento } \\
\text { Treatment }\end{array}$} & \multirow{3}{*}{$\begin{array}{c}\text { Média } \\
\text { Mean }\end{array}$} & \multirow{3}{*}{$\mathrm{CV}(\%)$} \\
\hline & & MFS1 & MFS2 & FTFS1 & FTFS2 & & \\
\hline & & CSBM1 & $C S B M 2$ & $W M S B M 1$ & WMSBM2 & & \\
\hline & & \multicolumn{6}{|c|}{ 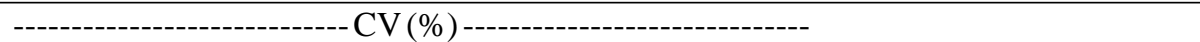 } \\
\hline $\mathrm{RD}(Y H Q)^{1}$ & $38,0^{\mathrm{a}}$ & $38,9^{\mathrm{a}}$ & $38,3^{\mathrm{a}}$ & $38,9^{\mathrm{a}}$ & $39,3^{\mathrm{a}}$ & 38,7 & 3,2 \\
\hline $\operatorname{RPAL}(\tilde{S Y})^{1}$ & $16,3^{\mathrm{a}}$ & $17,4^{\mathrm{a}}$ & $15,8^{\mathrm{a}}$ & $16,3^{\mathrm{a}}$ & $16,3^{\mathrm{a}}$ & 16,4 & 7,7 \\
\hline $\operatorname{RACÉM}(A Y)^{1}$ & $21,8^{\mathrm{a}}$ & $21,5^{\mathrm{a}}$ & $22,5^{\mathrm{a}}$ & $22,6^{\mathrm{a}}$ & $23,0^{\mathrm{a}}$ & 22,3 & 9,3 \\
\hline $\operatorname{RTT}(F Q Y)^{1}$ & $61,9^{\mathrm{a}}$ & $61,1^{\mathrm{a}}$ & $61,7^{\mathrm{a}}$ & $61,1^{\mathrm{a}}$ & $60,7^{\mathrm{a}}$ & 61,3 & 2,0 \\
\hline $\operatorname{RTE}(P S C Y)^{1}$ & $48,2^{\mathrm{a}}$ & $47,8^{\mathrm{a}}$ & $47,6^{\mathrm{a}}$ & $48,1^{\mathrm{a}}$ & $47,7^{\mathrm{a}}$ & 47,9 & 3,3 \\
\hline $\operatorname{RALC}(W R Y)^{1}$ & $19,3^{\mathrm{a}}$ & $19,8^{\mathrm{a}}$ & $19,5^{\mathrm{a}}$ & $19,8^{a}$ & $19,8^{a}$ & 19,7 & 3,2 \\
\hline $\operatorname{RCOX}(R Y)^{1}$ & $28,9^{\mathrm{a}}$ & $28,1^{\mathrm{a}}$ & $28,1^{\mathrm{a}}$ & $28,3^{\mathrm{a}}$ & $27,9^{\mathrm{a}}$ & 28,2 & 4,1 \\
\hline $\operatorname{RPA}(S R Y)^{1}$ & $13,7^{\mathrm{a}}$ & $13,2^{\mathrm{a}}$ & $14,1^{\mathrm{a}}$ & $12,9^{\mathrm{a}}$ & $12,9^{\mathrm{a}}$ & 13,4 & 7,1 \\
\hline
\end{tabular}

${ }_{1}^{1}$ Médias em uma mesma linha, seguidas por letras diferentes, são diferentes $(\mathrm{P}<0,05)$ pelo teste $\mathrm{F}$.

${ }^{1}$ Means, withim a row, followed by different letters are different $(P<.05)$ by $F$ test. 
os animais submetidos aos diferentes suplementos. Estes resultados estão de acordo com os obtidos por PERON (1991), que também não verificou diferenças marcantes entre os quartos dianteiro e traseiro, dos diferentes grupos raciais estudados, evidenciando-se, dessa forma, tendência de manutenção do equilíbrio entre os quartos traseiro e dianteiro, independente do peso de abate e do nível nutricional imposto ao animal (BERG e BUTERFIELD, 1979).

Os valores de comprimento de carcaça aparente (COMPCAR), espessura de gordura subcutânea (ESPGOR) e área de olho de lombo (AOL), expressos em termos absolutos ou por $100 \mathrm{~kg}$ de peso corporal vazio (PCVZ), para os animais submetidos às diferentes suplementações, são apresentados na Tabela 7.

Não houve diferença $(\mathrm{P}>0,05)$ entre os animais submetidos aos diferentes suplementos, quanto aos valores de COMPCAR, ESPGOR e AOL, expressos em valores absolutos ou por $100 \mathrm{~kg}$ de PCVZ.

De acordo com JORGE (1997a), quando o comprimento de carcaça é expresso por $100 \mathrm{~kg} \mathrm{PCVZ,} \mathrm{ou}$ o abate é feito a um peso constante, tem-se idéia de compacidade do animal. Não houve efeito da suplementação sobre este parâmetro neste estudo.

Os valores de COMPCAR por $100 \mathrm{~kg}$ PCVZ, para os novilhos mestiços Holandês-Zebu deste ex- perimento, são semelhantes aos encontrados por PERON (1991), utilizando animais, também castrados, com padrão genético similar ao deste estudo, porém em condições de confinamento.

A falta de efeito de suplementos sobre a espessura de gordura subcutânea indica ausência de diferenças marcantes quanto à maturidade fisiológica (terminação) entre os animais dos diferentes tratamentos. Os resultados obtidos com relação à ESPGOR, expressos em valores médios absolutos e por $100 \mathrm{~kg}$ PCVZ (7,45 e 2,09, respectivamente), foram superiores aos valores médios obtidos por PERON (1991) (3,0 e 0,86), com animais mestiços castrados em confinamento.

Espessura de gordura da carcaça entre 3 e $5 \mathrm{~mm}$ é importante para que se tenha melhor qualidade da carne, bem como para maior proteção no resfriamento da carcaça. Considerando-se que os valores obtidos no presente estudo foram superiores aos mínimos necessários para adequada proteção da carcaça, verifica-se que animais terminados em condições de pastagem podem apresentar acabamento de carcaça semelhante ao de animais confinados, desde que sejam propiciadas condições de pastejo adequadas.

Valores inferiores aos deste estudo para AOL, em valores absolutos ou por $100 \mathrm{~kg}$ de PCVZ, foram encontrados por PERON (1991), utilizando também

Tabela 7 - Médias e coeficientes de variação (CV\%) do comprimento de carcaça (COMPCAR), da espessura de gordura subcutânea (ESPGOR) e da área de olho de lombo (AOL), por tratamento

Table 7 - Means and coefficients of variation (CV\%) of carcass length (CL), backfat thickness (BFT) and loin eye area (LEA), per treatment

\begin{tabular}{|c|c|c|c|c|c|c|c|}
\hline \multirow[b]{2}{*}{ Itens } & \multirow[b]{2}{*}{$\begin{array}{l}\text { Sal } \\
\text { Salt }\end{array}$} & \multicolumn{4}{|c|}{$\begin{array}{c}\text { Tratamento } \\
\text { Treatment }\end{array}$} & \multirow[b]{2}{*}{$\begin{array}{l}\text { Médias } \\
\text { Means }\end{array}$} & \multirow[b]{2}{*}{$\mathrm{CV}(\%)$} \\
\hline & & $\begin{array}{l}\text { MFS1 } \\
\text { CSBM1 }\end{array}$ & $\begin{array}{l}\text { MFS2 } \\
C S B M 2\end{array}$ & $\begin{array}{c}\text { FTFS1 } \\
\text { WMSBM1 }\end{array}$ & $\begin{array}{c}\text { FTFS2 } \\
\text { WMSBM2 }\end{array}$ & & \\
\hline \multicolumn{8}{|c|}{$\begin{array}{l}\text {---------------- Valores absolutos --------------------- } \\
\text { Absolute values }\end{array}$} \\
\hline $\begin{array}{l}\text { COMPCAR }(\mathrm{cm})^{1} \\
C L\end{array}$ & $138^{a}$ & $136^{\mathrm{a}}$ & $138^{\mathrm{a}}$ & $138^{\mathrm{a}}$ & $134^{\mathrm{a}}$ & 136,8 & 3,8 \\
\hline $\begin{array}{l}\operatorname{ESPGOR}(\mathrm{mm})^{1} \\
B F T\end{array}$ & $7,43^{\mathrm{a}}$ & $6,83^{\mathrm{a}}$ & $8,03^{\mathrm{a}}$ & $6,67^{\mathrm{a}}$ & $8,27^{\mathrm{a}}$ & 7,45 & 30,9 \\
\hline \multicolumn{8}{|c|}{$\begin{array}{c}\text {------------- Peso corporal vazio }(\% \mathrm{PCVZ}) \text {---------------- } \\
\% E B\end{array}$} \\
\hline $\begin{array}{l}\text { COMPCAR }(\mathrm{cm})^{1} \\
C L\end{array}$ & $40^{\mathrm{a}}$ & $40^{\mathrm{a}}$ & $37^{\mathrm{a}}$ & $40^{\mathrm{a}}$ & $38^{\mathrm{a}}$ & 39 & 26,96 \\
\hline $\begin{array}{l}\mathrm{ESPGOR}(\mathrm{mm})^{1} \\
B F T\end{array}$ & $2,10^{\mathrm{a}}$ & $1,94^{\mathrm{a}}$ & $2,13^{\mathrm{a}}$ & $1,94^{\mathrm{a}}$ & $2,34^{\mathrm{a}}$ & 2,09 & 5,23 \\
\hline $\operatorname{AOL}\left(\mathrm{cm}^{2}\right)^{1}$ & $24,2^{\mathrm{a}}$ & $22,6^{a}$ & $22,2^{\mathrm{a}}$ & $26,5^{\mathrm{a}}$ & $26,2^{\mathrm{a}}$ & 24,3 & 14,5 \\
\hline
\end{tabular}


animais mestiços castrados, porém em confinamento. Resultados semelhantes aos deste estudo para AOL, expressa por $100 \mathrm{~kg}$ de PCVZ, foram encontrados por FEIJÓ e EUCLIDES FILHO (1998), em experimento avaliando o efeito de três sistemas de produção sob as características de carcaça e carne em dois grupos genéticos (F1 Abeerden Angus x Nelore e Simental $x$ Nelore), mantidos em regime de suplementação a pasto na primeira seca e confinados na segunda seca de suas vidas. Os animais castrados ao nascer apresentaram AOL de $27,5 \mathrm{~cm}$ e aqueles castrados à desmama, 27,1 cm.
As análises de variância para as proporções de músculos (\%M), tecido adiposo (\% TA) e ossos $(\% \mathrm{O})$ na carcaça mostraram não haver diferenças $(\mathrm{P}>0,05)$ entre as variáveis estudadas, para os animais submetidos aos diferentes tratamentos (Tabela 8).

Os valores referentes à $\% \mathrm{M}, \% \mathrm{TA}$ e $\% \mathrm{O}$, obtidos no presente estudo, foram semelhantes aos valores médios obtidos por PERON (1991), com animais mestiços castrados, 50; 33; e 17\%, respectivamente, e próximos aos de JORGE (1997), 55; 28; e 15\%, obtidos com animais zebuínos não-castrados, em confinamento.

Tabela 8 - Médias da proporção de músculos (M\%), tecido adiposo (TA\%) e ossos (O\%) e coeficientes de variação (CV\%), em função dos diferentes tratamentos

Table 8 - Means of muscles (M\%), adipose tissue (AT\%) and bone (B\%) proportions and coefficients of variation (CV\%), according to different treatments

\begin{tabular}{|c|c|c|c|c|c|c|c|}
\hline \multirow[b]{2}{*}{ Itens } & \multirow[b]{2}{*}{$\begin{array}{l}\text { Sal } \\
\text { Salt }\end{array}$} & \multicolumn{4}{|c|}{$\begin{array}{c}\text { Tratamento } \\
\text { Treatment }\end{array}$} & \multirow[b]{2}{*}{$\begin{array}{l}\text { Média } \\
\text { Mean }\end{array}$} & \multirow[b]{2}{*}{$\mathrm{CV}(\%)$} \\
\hline & & $\begin{array}{l}\text { MFS1 } \\
C S B M 1\end{array}$ & $\begin{array}{l}\text { MFS2 } \\
C S B M 2\end{array}$ & $\begin{array}{c}\text { FTFS1 } \\
W M S B M 1\end{array}$ & $\begin{array}{c}\text { FTFS2 } \\
W M S B M 2\end{array}$ & & \\
\hline $\mathrm{M}(M), \%^{1}$ & $51,8^{a}$ & $54,4^{\mathrm{a}}$ & $53,2^{\mathrm{a}}$ & $49,8^{\mathrm{a}}$ & $52,8^{\mathrm{a}}$ & 52,4 & 10,99 \\
\hline $\mathrm{TA}(A T), \%^{1}$ & $30,5^{\mathrm{a}}$ & $26,1^{\mathrm{a}}$ & $30,4^{\mathrm{a}}$ & $29,4^{\mathrm{a}}$ & $30,6^{\mathrm{a}}$ & 29,4 & 22,16 \\
\hline $\mathrm{O}(B), \%^{1}$ & $17,7^{\mathrm{a}}$ & $19,5^{\mathrm{a}}$ & $16,4^{\mathrm{a}}$ & $20,8^{a}$ & $16,6^{\mathrm{a}}$ & 18,2 & 25,89 \\
\hline
\end{tabular}

${ }^{1}$ Médias em uma mesma linha, seguidas por letras diferentes, são diferentes $(P<0,05)$ pelo teste $F$.

${ }^{1}$ Means, withim a row, followed by different letters are different $(P<.05)$ by $F$ test.

\section{Conclusões}

Em pastagens de Brachiaria decumbens, com alta disponibilidade de MS/ha (6736 kg), observou-se boa terminação de bovinos, sem necessidade de suplementação concentrada.

\section{Referências Bibliográficas}

BERG, R.T., BUTTERFIELD, R.M. 1979. El crescimiento del ganado vacuno y la producción de carne de vacuno In: Nuevos conceptos sobre desarrollo de ganado vacuno. Zaragoza: Acribia.. p.16-29.

CAMPOS, J. 1995. Tabelas para cálculo de rações. Viçosa: Imprensa Universitária. 2.ed. 64p.

DETMANN, E., PAULINO, M.F., ZERVOUDAKIS, J.T. et al. 2001. Suplementação de novilhos durante a época das águas: parâmetros ingestivos e digestivos. Rev. bras. zootec., 30(4):1340-1349.

EUCLIDES, V.P.B., EUCLIDES FILHO, K., ARRUDA, Z.J. et al. 1998. Desempenho de novilhos em pastagens de Brachiaria decumbens submetidos a diferentes regimes alimentares. R. Bras. Zootec., 27(2): 246-252.
FERREIRA, M.A., VALADARES FILHO, S.C., COELHO DA SILVA, J.F. et al. Desempenho de novilhos F1 Simental X Nelore alimentados com vários níveis de concentrado. In: REUNIÃO DA SOCIEDADE BRASILEIRA DE ZOOTECNIA, 34, Juiz de Fora, MG, 1997. Anais... Juiz de Fora, MG: SBZ, 1997. p.280.

FEIJÓ, G.L.D., EUCLIDES FILHO, K. Efeito de diferentes sistemas de produção sobre as características das carcaças de bovinos de dois grupos genéticos. In: SOCIEDADE BRASILEIRA DE ZOOTECNIA, 1998, Botucatu. Anais... Botucatu: SBZ, 1998.

HANKINS, O.G., HOWE, P.E. 1946. Estimation of the composition of beef carcasses and cuts. Washington, D.C (Tech. Bulletin - USDA, 926)

HESS, B.W., KRYSL, L.J., JUDKINS, M.B. et al. 1996. Supplemental corn or wheat bran for steers grazing endophytefree fescue pasture: effects on live weight gain, nutrient quality, forage intake, particulate and fluid kinetics, ruminal fermentation, and digestion. J. Anim. Sci., 74:1116-1125.

JORGE, A.M. Desempenho produtivo, características e composição corporal e da carcaça de zebuínos de quatro raças, abatidos em diferentes estágios de maturidade. Viçosa, MG: UFV, 1997. 99p. Tese (Doutorado em Zootecnia) - Universidade Federal de Viçosa, 1997. 
JORGE, A.M., FONTES, C.A.A., SOARES, J.E. et al. 1997a. Características quantitativas da carcaça de bovinos e bubalinos, abatidos em diferentes estádios de maturidade. $R$. Bras. Zootec., 26(5):1039-1047.

JORGE, A.M., FONTES, C.A.A., FREITAS, J.A. et al. 1997b. Rendimento da carcaça, e de cortes básicos de bovinos e bubalinos abatidos em diferentes estádios de maturidade. R. Bras. Zootec., 26(5):1048-1054.

LUCHIARI FILHO, A. 1998. Perspectivas da bovinocultura de corte no Brasil. In: SIMPÓSIO SOBRE PRODUÇÃO INTENSIVA DE GADO DE CORTE, Campinas, 1998. Anais...Campinas: CBNA, 1998. p.1-10.

McMENIMAN, N.P. Methods of estimating intake of grazing animals. In: Reunião Anual da Sociedade Brasileira de Zootecnia, 34, Juiz de fora, 1997. Anais... Juiz de fora: SBZ, 1997. p.131-168.

NATIONAL RESEARCH COUNCIL - NRC. 1996. Nutrient requirements of beef cattle. 7.ed. Washington, D.C. 243p.

NOLLER, C.H., NASCIMENTO JR., D., QUEIROZ, D.S. Exigências nutricionais de animais em pastejo. In: SIMPÓSIO SOBRE MANEJO DE PASTAGEM, 13, Piracicaba,1996. Anais... Piracicaba: FEALQ,1996. p.151-184.

PAULINO, M.F., REHFELD, O.A.M., RUAS, J.R.M. 1982. Alguns aspectos da suplementação de bovinos de corte em regime de pastagem durante a época seca. Inf. Agropec., 8(89):28-31.

PAULINO, M.F., BORGES, L.E., CARVALHO, P.P, et al. Fontes de proteína em suplementos múltiplos sobre o desenvolvimento de novilhos e novilhas mestiços em pastoreio durante a época das águas. In: REUNIÃO ANUAL DA
SOCIEDADE BRASILEIRA DE ZOOTECNIA, 1996, Fortaleza. Anais... Fortaleza: SBZ, 1996. p.12-13.

PERON, A.J. Características e composição física e química, corporal e da carcaça de bovinos de cinco grupos genéticos, submetidos à alimentação restrita e "ad libitum". Viçosa, MG: UFV, 1991. 126p. Dissertação (Mestrado em Zootecnia) - Universidade Federal de Viçosa, 1991.

SILVA, D.J. 1990. Análise de alimentos: métodos químicos e biológicos. Viçosa: UFV. 165p.

SNIFFEN, C.J., O'CONNOR, J.D., VAN SOEST, P.J. et al. 1992. A net carbohydrate and protein sytem for evaluating cattle diets: II - Carbohydrate and protein availability. J. Anim. Sci., 70:3562-3577.

UNIVERSIDADE FEDERAL DE VIÇOSA - UFV. SAEG Sistema de análises estatísticas e genética. Viçosa, MG, 1995. (Apostila).

VAN SOEST, P.J., ROBERTSON, J.B., LEWIS, B.A. 1991 Methods for dietary fiber, and nonstarch polysaccharides in relation to animal nutrition. J. Dairy Sci., 74(10):3583-3597.

Recebido em: $28 / 08 / 00$

Aceito em: 30/03/01 